Nuevamente hallamos aquí la fusión de símbolos religiosos con los de inspiración puramente primitiva y arquetípica.

El estudio del simbolismo del sol en la poesía de Lorca nos revela, por consiguiente, una vez más, su carácter cósmico y nos da una clave para conocer la índole de su inspiración y el horizonte de su mundo lírico. La visión imaginística y metafórica queda pronto superada por una perspectiva simbólica de características trascendentes. La presencia desgarrada del astro a la hora del atardecer y del amanecer traduce la frustración de la vida afectiva del poeta y es un poderoso símbolo del destino humano violentamente truncado. Asimismo, la fragilidad de la criatura mítica es representativa de la ausencia de realización espiritual. Finalmente, la identificación del sol con divinidades cristianas y arquetípicas confiere a la vida del hombre una dimensión sacramental y religiosa.

Gustavo Correa

Yale University

\title{
TRADICIÓN Y NOVEDAD EN UN POEMA DE JULIÁN DEL CASAL
}

Se ha realizado ya, con esmerada erudición (caso tal vez único en la crítica hispanoamericana), el estudio de las influencias extranjeras en la obra de Casal. Pero, a pesar de la exactitud con que se pueden medir sus deudas para con la literatura francesa que tanto amaba, y de la paciencia con que se han señalado en su verso los ecos conscientes e inconscientes de sus lecturas, el lector de Casal se siente perdido todavía, sin una clave de comprensión o valoración. El enigma de la personalidad de Julián del Casal parece repetirse en su obra.

La obra, en realidad, no es sino reflejo lejano de una biografía o de los pormenores de una vida de la cual nos interesa aquí solamente lo definidor, la melancolía y el tedio sin causa tantas veces expresados en el poeta, "la tristeza profunda de ser hombre". Es costumbre describir la angustia nihilista de Casal y colocarlo entre los primeros modernistas, la generación de iniciadores, como un innovador que tomó de Baudelaire y del parnasianismo determinadas formas e ideas y directivas poéticas que se incorporarían luego a la literatura hispánica. De esa manera se oculta a veces, con el ánalisis del detalle, una verdad más honda: la tradicionalidad de la poesía de Casal. De ahí que se haya descuidado el estudio de los pocos momentos válidos de su obra, para hacer hincapié en la profusión de reflejos de lo extranjero. Se ha olvidado que en todo estudio de literatura comparada deben ir de la mano la indicación de la fuente extranjera y la definición de la originalidad del autor que la incorpora a su obra propia.

Y lo más original y propio es a menudo lo tradicional que se renueva en una mentalidad moderna. A pesar de las lecturas extranjeras, se afirma

la fiesta de San Juan Bautista es el 24 de junio, fecha que corresponde casi exactamente al solsticio de verano. 
a veces en Casal la fuerza de los "concetos" que se habían depositado en el fondo de su espíritu gracias a las lecturas hechas de niño o adolescente, y, cuando tales "concetos" brotan sin imitación consciente en la madurez de pensamiento o sentimiento, el eco es sutilmente despistador. Por esta razón parece posible volver a analizar la poesía de Casal aun después de los estudios de Gustavo Duplessis y de José María Monner Sans, el primero un trabajo detallado y valioso, y el segundo una introducción ejemplar al estudio de conjunto del modernismo hispanoamericano ${ }^{1}$. Lo que queda por hacer es posible sólo en función de la existencia de estos trabajos y a base de sus conclusiones y hallazgos: la búsqueda de un punto fijo que nos grabe la personalidad poética de Casal. Se ha de fundar esta búsqueda en la poda previa de lo superficial y deleznable, y deberá llegar, finalmente, al encuentro de un poema, al menos, en que se decida con toda claridad el valor posible de su obra.

En la obra de Casal, más que en la de otros modernistas, es patente la influencia de Baudelaire, no sólo porque el cubano lo conocía mejor, sino también porque esta influencia, cuando aflora, no está asimilada en poesía propia, sino más bien aparece como algo añadido, como cita de admiración, o seguida de cerca en ecos que no se atreven a fundir los sonidos con otros para producir algo distinto. La misma veneración de Casal por Baudelaire le ha impedido a veces hacer suyos los métodos profundos que el francés había anunciado y que hereda la poesía moderna. Se ha apoderado Casal de lo externo, de la "forma mucho mejor que del fondo de la poesía baudeleriana" (D, 151).

Por lo pronto, parece claro que Casal admiraba a Baudelaire casi hasta el punto de excluir a otros poetas, y quizá el "bardo único" de quien habla en su poema $A$ la belleza sea el propio Baudelaire (el poema lleva como epígrafe una famosa estrofa de Bénédiction), aunque no es posible afirmarlo inequívocamente. Como su maestro francés, tiene Casal el "impuro amor de las ciudades" y se escapa del lugar en que le ha tocado vivir hacia todos los exotismos, en viajes imaginarios. De Baudelaire también, más que de su propia experiencia, deriva su "hastío glacial". Aún más inmediato es ese parentesco en La canción de la morfina, que repite el interés decadente por los paraísos artificiales. Un parecido, ya señalado por la crítica, con el poema L'albatross se da en la imagen final del soneto $E l$ arte, y también la técnica misma de este poema de Baudelaire, la "descripción inicial para en ella apoyar la comparación consecuente", parece darle la pauta que sigue en Mi ensueño (M, 54). Gusta Casal, además, del "detalle macabro en que se presienten emanaciones cadavéricas. Sin embargo, no iguala en esto a Baudelaire"2.

Precisamente su interés acendrado por los temas ha desviado a Casal y le ha impedido encontrar lo esencial de Baudelaire en la manera, en la novedad de la creación poética por medio de la evocación. Lo superficial y fácil de asir, la idea de que hay posibilidades de comparación entre distintas sensaciones, sí que aparece. Pero nunca se crea en su poema la atmósfera de evocación alucinante que caracteriza a los mejores poemas

1 Gustavo Duplessis, "Julián del Casal", $R B C$, 54 (1944), 31-75, 140-170, 241-283; José María Monner Sans, Julián del Casal y el modernismo hispanoamericano, México, 1952. Abreviaré en adelante, respectivamente, D y M.

2 Arturo Torres-Rioseco, Precursores del modernismo, Madrid, 1925, p. 42. 
de Baudelaire. Aunque la sinestesia como juego de sensaciones haya recibido más atención crítica de la que merece, es la teoría recóndita de la evocación por medio de las sensaciones la que define el hallazgo de un método poético en Baudelaire. Para comprender este método bastará recordar uno de los poemas, La Chevelure, donde está empleado con mayor fortuna. Partiendo del perfume indefinible de una cabellera, por asociación de este perfume y los olores embriagantes de un país lejano, se crea una visión mágica del Asia. No debe confundirse este método de creación artística con el fenómeno psíquico, frecuentemente anormal, de la sinestesia. En éste, el estímulo de un sentido se confunde con la respuesta de otro, y el fenómeno en sí no tiene función estética, aunque pueda ser usado en poesía para ciertos fines de decoración poética o como centro de un concepto de la realidad. En la evocación, por el contrario, nos hallamos de lleno en el terreno de la creación, que consiste en traer un mundo imaginado a la vida mental del lector a través de la experiencia misma, vivida o soñada, que se interpreta. En La Chevelure se interpreta un momento de pasión ardiente en una alucinación de mundos intercambiables. El procedimiento se repite en otros poemas de Baudelaire; baste, como ejemplo, un fragmento de Parfum exotique:

Guidé par ton odeur vers de charmants climats,

je vois un port rempli de voiles et de mâts

encor tout fatigués par la vague marine,

pendant que le parfum des verts tamariniers,

qui circule dans l'air et m'enfle la narine,

se mêle dans mon âme au chant des mariniers.

Para afianzar la comprensión de ese método y de lo que puede significar una influencia profunda, comparemos este poema con otro muy posterior, en el cual se emplea el mismo procedimiento no para recordar soles exóticos, sino para reproducir melancólicamente una nostalgia. A partir de una sensación auditiva, en vez de la olfativa de Baudelaire, nos transporta Jorge Luis Borges, en La guitarra, del momento mismo de la presencia del sonido en la prosa cotidiana del arrabal, al mundo pictórico de una distante geografía:

\author{
He mirado la Pampa \\ de un patiecito de la calle Sarandí en Buenos Aires. \\ Cuando entré no la vi. \\ Estaba acurrucada \\ en lo profundo de una brusca guitarra. \\ Sólo se desmelenó \\ al entreverar la diestra las cuerdas. \\ No sé lo que azuzaban; \\ a lo mejor fue un triste del Norte \\ pero yo vi la Pampa.
}

La Pampa, en el poema de Borges, adquiere la misma presencia inescapable con que se imponía el Asia en La Chevelure. La influencia de Baudelaire en lo más hondo de la concepción poética es innegable; no habría habido ni siquiera la posibilidad de pensar de esta manera sin la obra de Baudelaire, y, no obstante, la originalidad del argentino está patente desde la experiencia misma. Lo que ha hecho Borges es asimilar 
un procedimiento artístico para expresar a través de sus posibilidades lo propio suyo.

Por el contrario, en Casal la relación es de una dependencia a la vez mayor, de eco directo, y menor, porque él nunca se detiene a estudiar e incorporar las doctrinas de Baudelaire en su propia poesía. Lo que quiere decir que el valor de Casal no puede definirse en relación con la influencia de Baudelaire; sólo se puede señalar esta influencia como algo externo que, una vez puesto a un lado, nos permitirá examinar lo esencial de su poesía. Pero antes es necesario establecer otro punto de referencia: la relación de su poesía con el Parnaso post-baudeleriano, cuidadosamente estudiado por Casal. Como esta parte de su obra - la que sigue de cerca los principios de objetividad y refinamiento técnico propios del Parnaso francés- es la más extensa, tendremos que aceptar el juicio poco halagador que reduce a Casal a "lo que podríamos llamar un virtuoso de la rima" 3 , y añadir que no mira la naturaleza "con el propósito de expresar estados de alma a la manera romántica, sino complaciéndose, parnasianamente, en el empaste multicolor y decorativo de cada cuadro, fiesta ofrecida a sus ojos" (M, 53).

Desde sus deudas para con Gautier y Huysmans ${ }^{4}$ hasta sus lecturas de Banville y Leconte de Lisle $\left(M, 5^{2}\right)$ y sus traducciones e imitaciones de Heredia y aun de Louis Bouilhet (D, 148-149), todas las imitaciones directas de los parnasianos y los ecos que salpican aquí y allá una obra titubeante han sido señalados ya; no queda por hacer sino el inventario de esta influencia parnasiana, preguntarse si algo quedó, si aprendió algo el poeta en esta larga esclavitud. Para ello nada mejor que un rápido examen del soneto Elena, de indudable filiación parnasiano-decadente, ya que pertenece a la serie "Mi museo ideal", inspirada en los cuadros de Gustave Moreau, de los cuales tenía conocimiento Casal a través de Huysmans. Un libro decadente, À Rebours, un pintor decadente y la técnica de descripción pictórica objetiva de un tema de la antigüedad clásica preconizada por el Parnaso, son los elementos que constituyen el soneto:

Luz fosfórica entreabre claras brechas en la celeste inmensidad. y alumbra del foso en la fatídica penumbra cuerpos hendidos por doradas flechas.

Cual humo frío de homicidas mechas, en la atmósfera densa se vislumbra vapor disuelto que la brisa encumbra a las torres de Ilión, escombros hechas.

Envuelta en veste de opalina gasa, recamada de oro, desde el monte de ruinas hacinadas en el llano,

indiferente a lo que en torno pasa, mira Elena hacia el lívido horizonte irguiendo un lirio en la rosada mano.

3 TORRES-Rioseco, op. cit., p. $5^{2}$.

"Véase "À Rebours y dos sonetos de Julián del Casal", en A. Torres-Rioseco, Ensayos sobre literatura latinoamericana, Segunda serie, México, 1958, pp. 90-92. 
El cuadro no admite la presencia del poeta, su queja o su aprobación. En la frialdad más absoluta se desarrolla, más bien se abre la escena, y aun el "cual" del quinto verso, que debería indicar la intervención del sujeto pensante, se desvirtúa inmediatamente para dar a la comparación casi la inevitabilidad de una existencia en sí, reducido el todo a un "humo frío" que se encumbra hacia las distantes torres de Ilión. Todo el horror del horizonte rojo no alcanza a deshacer la calma indiferente de la belleza de Elena, presente en su lirio y en la sugestión de color de su mano.

Dentro de los límites exiguos de la técnica que se ha impuesto el poeta, los sonetos de "Mi museo ideal", y Elena sobre todo, tienen el relativo valor de su competencia: el verso es exacto, la rima bien hallada, el cuadro completo, sin concesiones a la facilidad. A pesar de ello, no nos queda más remedio que aceptar el juicio de la posteridad y admitir un mero valor de documento histórico para esta parte de la obra de Casal. Pero habrá que admitir también que el hecho mismo de intentar una absoluta perfección técnica ha dado al soneto un mayor rigor, no sólo en los poetas que vendrán después, sino también en el mismo Casal, que, si bien no consiguió en su parnasianismo legar la poesía grandiosa que quizá había soñado escribir, alcanzó a través de él una habilidad de versificador que no habría logrado sin esa disciplina literaria.

Lo céntrico del pensamiento de Casal, al parecer derivado de Baudelaire, se halla en la monótona afirmación de su tedio vital, mientras que del Parnaso ha heredado una habilidad técnica y una preocupación por el detalle de la versificación que son poco comunes en su tiempo. No obstante, para comprender su poesía nos hace falta un asidero más. Por lo pronto, se ha insinuado ya, aunque débilmente, que la poesía de su idioma, la tradición suya, no está ausente por completo de la obra de Casal. Además de la tradicionalidad de los metros (M, 48), se ha señalado en un poema de su primer libro un momento que recuerda a Garcilaso: "Sus labios de carmín, que afrenta fueron / de las fragantes rosas encarnadas" (D, 142). Asimismo, en el capítulo "La iniciación del poeta" (M, 40-48), reseña Monner Sans los titubeos zorrillescos y las reminiscencias de Núñez de Arce o Campoamor en este primer libro de Casal.

Lo que resulta extraño es no encontrar una fusión de lo primario, las lecturas de su propia tradición, con las novedades aprendidas en Baudelaire y en el Parnaso. En primer lugar, observemos, para así establecer las preferencias de Casal en sus recuerdos de la poesía castellana, que el eco mencionado de Garcilaso, aunque tiene algo de la armonía garcilasiana, se inclina más hacia aquellas maneras renacentistas que va a exaltar Góngora más tarde, las exageraciones y los retruécanos culteranos que van a ser parte del barroco y que tienen su base en los juegos poéticos de la literatura cortesana del siglo xv. He aquí al menos una pista para adentrarnos por los gustos de Casal.

Asimismo el tedio y el deseo de morir para descansar, una idea muy española, se unen en Nostalgias, de su segundo libro, Nieves, para expresarse en la muy tradicional copla de pie quebrado:

Mas no parto. Si partiera,

al instante yo quisiera

regresar. 
¡Ay! ¿Cuándo querrá el destino que yo pueda en mi camino reparar?

Toda su pesadumbre de moda modernista se concentra para rememorar un anhelo ancestral de la cultura hispánica, pero todavía no alcanza la perfección formal que le podría dar su aprendizaje parnasiano. Sólo en su libro póstumo reaparece el grito de un deseo amargo, esta vez en la perfección acabada del endecasílabo:

y más me tarda cuanto más la ansío
y más la ansío cuanto más me tarda.

El eco de la célebre copla del Comendador Escrivá es seguro, pero está aquí asimilado de tal manera que, si tras los versos de Casal leemos los de la copla antigua,

Ven muerte tan escondida que no te sienta conmigo, porqu'el gozo de contigo no me torne a dar la vida ${ }^{5}$,

vemos que nos hallamos ante dos hechos poéticos relacionados, pero absolutamente distintos. En el moderno, por otra parte, se ha incorporado a la paradoja tradicional una lejana alusión al místico "que muero porque no muero" y se ha transportado la abstracta consideración de la muerte en general a la muy concreta presentación del tiempo que se desliza hora tras hora. En este último detalle se acerca Casal al pensamiento del siglo $\mathrm{xx}$ y prepara las preocupaciones de los poetas modernos españoles por un tema tradicional que se refuerza al contacto con la filosofía francesa y que, por consiguiente, no puede considerarse privativo ni aun significativo en la obra de la Generación del 98. Si así fuera, Casal, entre otros hispanoamericanos, debería ser incorporado a esa Generación ${ }^{6}$.

Así pues, en los dos versos citados de Casal se moderniza la tradición. El poema entero, el soneto Las horas, nos trae a este rotundo final, pasando por una comparación muy parecida a la que se daba en el soneto Elena -una comparación que empuja las horas a un horizonte de cuadro parnasiano, en medio de un paisaje irreal aunque claramente delineado en sonido y color:

¡Qué tristes son las horas! Cual rebaño de ovejas que caminan por el cieno, entre el fragor horrísono del trueno y bajo un cielo de color de estaño, cruzan sombrías en tropel huraño de la insondable Eternidad el seno,

${ }^{5}$ Esta famosa copla de la tradición ascético-mística castellana se encuentra, en versión distinta, en el Quijote, II, 38, y puede que así la conociera Casal: "Ven, muerte, tan escondida, / que no te sienta venir, / porque el placer de morir / no me torne a dar la vida".

- En su libro Modernismo frente a Noventa y ocho (Madrid, 1951), Gulllermo Díaz Plaja usa este concepto del tiempo, entre otros, para oponer dos grupos de escritores del momento. 
sin que me traigan ningún bien terreno ni siquiera el temor de un mal extraño.

Yo las siento pasar sin dejar huellas, cual pasan por el cielo las estrellas, $y$, aunque siempre la última acobarda de no verla llegar ya desconfío, y más me tarda cuanto más la ansío y más la ansío cuanto más me tarda.

El principio parnasiano del soneto, el cuadro de indiferencia cósmica, y el latido final de lamento, de desesperanza, de angustia, que es de lo mejor de Casal, se unen gracias a la irrupción nada parnasiana del protagonista, que invalida y hace resaltar así la frialdad del comienzo y continúa inmediatamente con la refundición de un dicho clásico, latino esta vez, "vulnerant omnes, ultima necat", para expresar la sensibilidad más apocada, más medrosa, de nuestro mundo moderno: "siempre la última acobarda". La conjunción de lo tradicional y de las novedades del aprendizaje parnasiano en el tema fundamental del pensamiento de Casal, ha producido un soneto de excepcional claridad, en el que el enigma de su poesía se resuelve en perfección. Quizá sea injusto ver la poesía de Casal sólo a través de estos pocos versos, cuando tanto en ella es deleznable. Sin embargo, se impone una nueva lectura del soneto Las horas, después de analizar las superficialidades que marcan un largo aprendizaje, si queremos comprender todo el tedio glacial que la poesía modernista adoptó del extranjero como algo postizo, pero que Casal supo entroncar con otro tema muy antiguo para expresar en un soneto la definición de su personalidad.

Bernardo Gicovate

Tulane University. 